\title{
Synthesis of Potent Bicyclic Bis-Arylimidazole C-Jun N-Terminal Kinase Inhibitors by Catalytic C-H Bond Activation
}

\author{
Jason C. Rech ${ }^{\dagger}$, Michihisa Yato $^{\dagger}$, Derek $_{\star}$ Duckett $^{\ddagger}$, Brian Ember $^{\ddagger}$, Philip V. LoGrasso ${ }^{\ddagger}$, Robert \\ G. Bergman ${ }^{\star}, \dagger$, and Jonathan A. Ellman ${ }^{\star}, \dagger$ \\ Department of Chemistry, University of California, and Division of Chemical Sciences, Lawrence \\ Berkeley National Laboratory, Berkeley, California, 94729
}

\begin{abstract}
$\mathrm{F}$

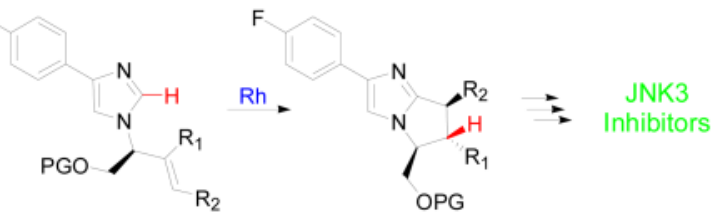

The efficient preparation of the privileged bicyclic bis-arylimidazole kinase inhibitor scaffold was accomplished using rhodium-catalyzed $\mathrm{C}-\mathrm{H}$ activation and intramolecular alkylation. The key $\mathrm{C}-\mathrm{H}$ activation/alkylation step represents one of the first evaluations of acyclic stereocontrol in catalyzed $\mathrm{C}-\mathrm{H}$ activation/olefin alkylation processes. Several inhibitors of JNK3 were prepared using this sequence, with the most potent inhibitor having an $\mathrm{IC}_{50}$ value of $1.6 \mathrm{nM}$.
\end{abstract}

The privileged bis-arylimidazole framework is found in a variety of potent kinase inhibitors, some of which have entered clinical trials. Bicyclic bis-arylimidazole derivatives, such as the c-jun N-terminal kinase 3 (JNK3) inhibitor 1 (Figure 1), ${ }^{1}$ have recently been developed to enhance affinity and particularly selectivity, which remains a key challenge in kinase inhibitor drug discovery efforts.

Bicyclic bis-arylimidazole inhibitors, exemplified by inhibitor 1, represent challenging synthetic targets. Indeed, the synthesis of $\mathbf{1}$ required 14 linear steps and was accomplished in less than $6 \%$ overall yield. ${ }^{1}$ Herein, we report an efficient asymmetric synthesis of $\mathbf{1}$ in 11 linear steps and $13 \%$ overall yield with the key bicyclic imidazole core generated through catalytic $\mathrm{C}-\mathrm{H}$ bond functionalization. We also successfully incorporated substituents in the $\mathrm{C} 7$ and $\mathrm{C} 8$ positions, substitution patterns difficult to access by the previously reported synthetic route, and in doing so observed the first examples of acyclic stereocontrol in metal-catalyzed $\mathrm{C}-\mathrm{H}$ bond activation. Moreover, evaluation of the compounds synthesized by this route resulted in the identification of a JNK3 inhibitor even more potent than $\mathbf{1}$.

In our retrosynthetic analysis of the bicyclic bis-arylimidazole framework, we envisioned installing the $\mathrm{C} 5$ pyrimidine by a cross-coupling with 2 (Figure 1). Synthesis of the bicyclic imidazole core would be accomplished via rhodium-catalyzed $\mathrm{C}-\mathrm{H}$ activation/annulation of 3. A van Leusen cycloaddition could be employed to generate $\mathbf{3}$ from $\mathbf{4}$, which can be readily prepared from commercially available starting material.

Email: bergman@cchem.berkeley.edu; jellman@uclink.berkeley.edu.

University of California, Berkeley

The Scripps Research Institute, Florida 
The synthesis of inhibitor $\mathbf{1}$ commenced with the condensation of $\left(S_{S}\right)$-tert-butanesulfinamide and commercially available tert-butyldimethylsiloxyacetaldehyde to provide $\mathbf{5}$ in $86 \%$ yield (Scheme 1). ${ }^{2}$ The addition of vinylmagnesium bromide to 5 proceeded with $91: 9 \mathrm{dr}$, and after chromatography, the major diastereomer was obtained in $69 \%$ yield. Acidic cleavage of the silyl and tert-butanesulfinyl groups provided 6 in nearly quantitative yield. ${ }^{2}$ Condensation of 6 with glyoxylic acid followed by treatment with 4-fluorophenyl tosylmethyl isonitrile ${ }^{3}$ generated the desired enantiomerically pure imidazole in $92 \%$ yield. ${ }^{4}$ Protection of the resulting primary alcohol as a tert-butyl diphenyl silyl (TBDPS) ether provided 7 in $98 \%$ yield.

Due to the steric hindrance introduced by the $\mathrm{C} 6$ substituent, forcing conditions were required to achieve good conversion in the $\mathrm{C}-\mathrm{H}$ activation/annulation step. Ultimately, cyclization of 7 was accomplished by using $5 \%\left[\mathrm{RhCl}(\mathrm{coe})_{2}\right]_{2}$ and $15 \% \mathrm{PCy}_{3}$ to generate the active catalyst with $5 \% \mathrm{MgBr}_{2}$ as an additive and toluene as solvent at $180{ }^{\circ} \mathrm{C}$ to provide 8 in $50 \%$ yield and with $92 \%$ ee (Scheme 1). ${ }^{5}$ Olefin isomerization and olefin reduction products were also isolated in $11 \%$ and $6 \%$ yield, respectively. Competitive olefin isomerization has been shown to occur under these conditions and is likely responsible for the minor erosion of enantiomeric excess observed during the cyclization. $5 \mathrm{c}$

Treatment of 8 with $\mathrm{Br}_{2}$ resulted in bromination of the imidazole ring at the $\mathrm{C} 5$ position in $94 \%$ yield. The resulting bromide was subjected to Stille cross coupling conditions in the presence of 2-methylthio-4-trimethylstannylpyrimidine ${ }^{6}$ to provide 9 in $85 \%$ yield (Scheme 1). ${ }^{7}$ The requisite amine was generated by oxidation of the thioether to the sulfone ( $79 \%$ yield) followed by addition of propylamine (78\% yield). Quantitative $\mathrm{Bu}_{4} \mathrm{NF}$ cleavage of the silyl ether provided 1 in $13 \%$ overall yield.

To demonstrate the flexibility of our synthetic approach toward bicyclic bis-arylimidazole systems and to explore acyclic stereocontrol in the $\mathrm{C}-\mathrm{H}$ activation/annulation step, we generated derivatives of $\mathbf{1}$ containing methyl substituents at the $\mathrm{C} 7$ or $\mathrm{C} 8$ positions. By employing isopropenylmagnesium bromide in place of vinylmagnesium bromide in the previously described sequence we were poised to generate a derivative with a $\mathrm{C} 7$ methyl substituent (Scheme 2). The sequence proceeded smoothly with excellent yields and selectivity for the generation of enantiomerically pure $\mathbf{1 1}(\mathbf{7 8 \%}$ from $\mathbf{5})$.

Treatment of $\mathbf{1 1}$ with the previously described rhodium-catalyzed $\mathrm{C}-\mathrm{H}$ activation/annulation conditions resulted in the formation of $\mathbf{1 2}$ in $61 \%$ yield as a 3:1 mixture of inseparable diastereomers (Scheme 2). ${ }^{5}$ The tetrasubstituted olefin isomerization and olefin reduction products also were isolated in $24 \%$ and $3 \%$ yields, respectively. For operational simplicity the diastereomers were separated at a later stage in the synthesis.

Bromination of $\mathbf{1 2}$ proceeded in $96 \%$ yield, and subsequent Stille cross-coupling installed the requisite arene at the $\mathrm{C} 5$ position in $66 \%$ yield (Scheme 2$).{ }^{7}$ Oxidative sulfone formation proceeded in quantitative yield and allowed for separation of the diastereomeric mixture by silica gel chromatography. Sulfone displacement and silyl ether cleavage then provided the C7 methyl derivative $\mathbf{1 3}$ in $15 \%$ overall yield from the commercially available tertbutyldimethylsiloxy-acetaldehyde.

The C8 methyl derivative was generated in a similar fashion (Scheme 3). The addition of allylmagnesium bromide to imine $\mathbf{5}$ proceeded with excellent yield and selectivity. Subsequent transformations generated enantiomerically pure $\mathbf{1 5}$ in excellent overall yield (67\% from 5). Treatment of 15 with $\left[\mathrm{RhCl}(\mathrm{coe})_{2}\right]_{2}$ in the presence of $\mathrm{PCy}_{3}$ and $\mathrm{MgBr}_{2}$ at $180{ }^{\circ} \mathrm{C}$ provided the bicyclic imidazole core with $86: 14 \mathrm{dr}$ and allowed for the isolation of $\mathbf{1 6}$ as a single diastereomer in $52 \%$ yield with $92 \%$ ee (Scheme 3 ). ${ }^{5}$ Consistent with previous studies, olefin isomerization to the internal disubstituted position occurs prior to annulation. ${ }^{5 \mathrm{c}}$ Completion of the synthesis was accomplished by bromination of $\mathbf{1 6}$, Stille cross-coupling ${ }^{7}$ to install the 
pyrimidine, oxidation and formal nucleophilic displacement of the resulting sulphone, and silyl ether cleavage to provide $\mathbf{1 7}$ ( $61 \%$ from 16). The overall yield for the preparation of the $\mathrm{C} 8$ methyl derivative $\mathbf{1 7}$ from the common aldehyde starting material was $18 \%$.

The ability of compounds 13 and $\mathbf{1 7}$, and their enantiomers ent-13 and ent-17 8 prepared by employing $\left(R_{S}\right)$-tert-butanesulfinamide in the previously described synthetic sequences, to inhibit JNK3 were determined (Table 1). While potency comparable to 1 was observed for 13, 17 and ent-17, a three to four-fold increase in potency was observed for ent-13.

In summary, we have developed an efficient and flexible synthetic route for the generation of the potent kinase inhibitor $\mathbf{1}$ with the key transformation being intramolecular alkylation via rhodium-catalyzed C-H bond activation. By utilizing this intramolecular alkylation, our approach easily allows for the introduction of substituents at the $\mathrm{C} 7$ and $\mathrm{C} 8$ positions, derivatives that would be much more difficult to access by the previously published route to 1. Determination of the selectivity profiles of the synthesized analogues and preparation of even more potent compounds are in progress.

\section{Supplementary Material}

Refer to Web version on PubMed Central for supplementary material.

\section{Acknowledgements}

This work was supported by the NIH GM069559 to J.A.E., the Director and Office of Energy Research, Office of Basic Energy Sciences, Chemical Sciences Division, U.S. Department of Energy, under Contract DEAC03-76SF00098 to R.G.B. Support for M.Y. by Sankyo is also gratefully acknowledged.

\section{References}

1. Graczyk PP, et al. Bioorg \& Med Chem Lett 2005;15:4666-4670. [PubMed: 16153829]

2. Tang TP, Volkman SK, Ellman JA. J Org Chem 2001;66:8772-8778. [PubMed: 11749605]

3. Sisko J, Mellinger M, Sheldrake PW, Baine NH. Tetrahedron Lett 1996;37:8113-8116.

4. Sisko J, Kassick AJ, Mellinger M, Filan JJ, Allen A, Olsen MA. J Org Chem 2000;65:1516-1524. [PubMed: 10814116]

5. (a) Weidemann SH, Lewis JC, Ellman JA, Bergman RG. J Am Chem Soc 2006;128:2452-2462. [PubMed: 16478202] (b) Tan KL, Bergman RG, Ellman JA. J Am Chem Soc 2002;124:3203-3205.

(c) Tan KL, Bergman RG, Ellman JA. J Am Chem Soc 2001;123:2685-2686. [PubMed: 11456947]

6. Ahaidar A, Fernandez D, Danilon G, Cuevas C, Manzanares I, Albericio F, Joule JA, Alvarez M. J Org Chem 2003;68:10020-10029. [PubMed: 14682696]

7. Alvarez M, Fernandez D, Joule JA. Tetrahedron Lett 2001;42:315-317.

8. Researchers at Easai had previously demonstrated that ent-1 had inhibitory activity comparable to that of 1.1 


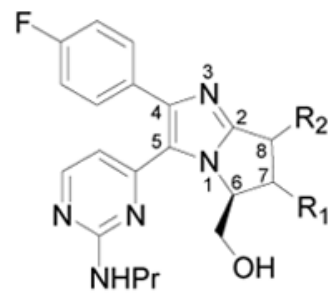

1: $\mathrm{R}_{1}=\mathrm{H}, \mathrm{R}_{2}=\mathrm{H}$

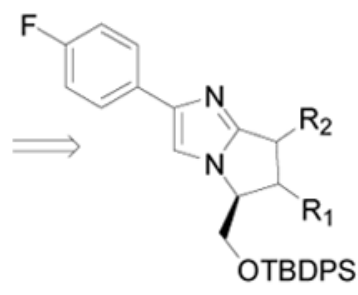

2

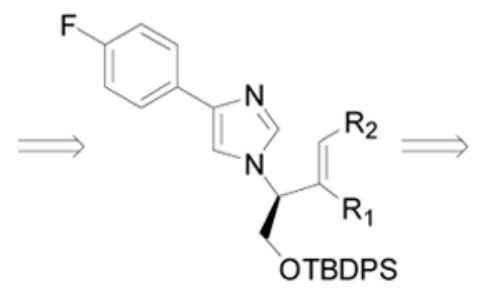

3<smiles>[R2]C=C([R])[C@@H](CO)NC</smiles>

4

Figure 1.

Retrosynthesis of Bicyclic Bis-Arylimidazole Kinase Inhibitors 


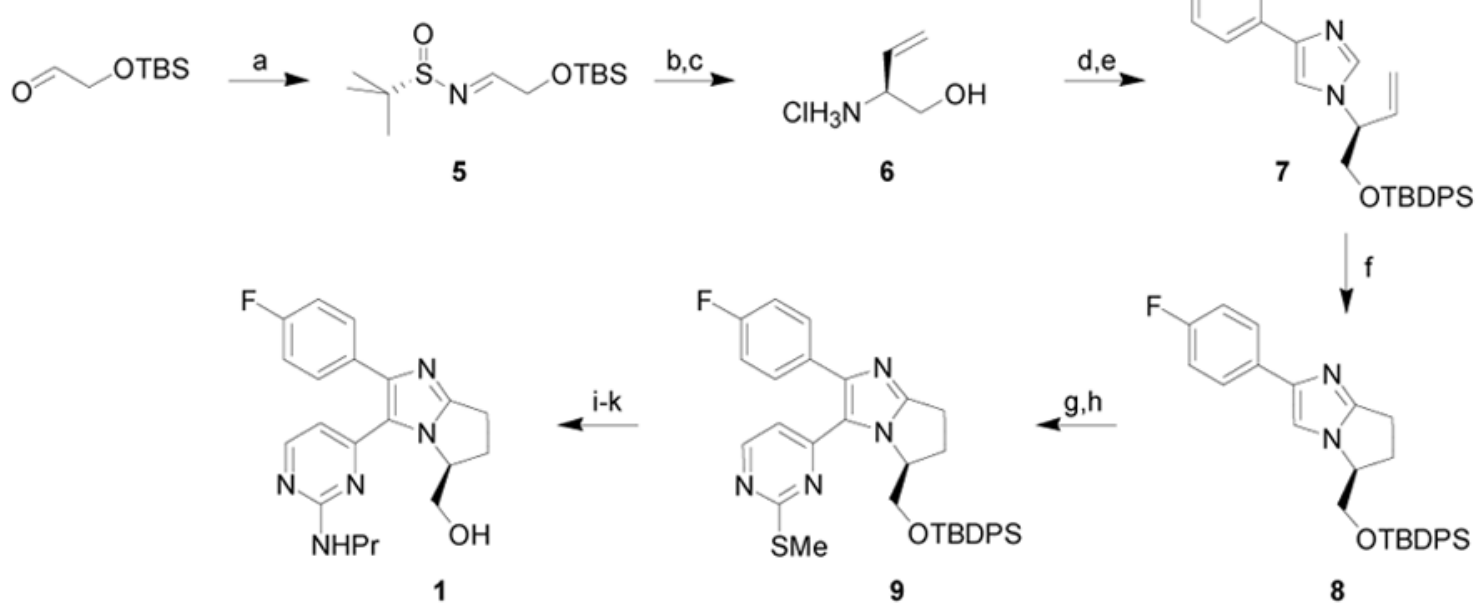

Scheme 1.

Synthesis of Inhibitor 1

Conditions: (a) $\left(S_{S}\right)$-tert-butanesulfinamide, $\mathrm{CuSO}_{4}, \mathrm{CH}_{2} \mathrm{Cl}_{2}, 86 \%$; (b) vinylmagnesium bromide, $\mathrm{CH}_{2} \mathrm{Cl}_{2}, 0{ }^{\circ} \mathrm{C}$ to rt, $69 \%$ (single diastereomer); (c) $4 \mathrm{~N} \mathrm{HCl}, \mathrm{CH}_{3} \mathrm{OH}, 99 \%$; (d) 4fluorophenyl tosylmethyl isonitrile ${ }^{3}$, glyoxylic acid, $\mathrm{K}_{2} \mathrm{CO}_{3}$, DMF, $92 \%$; (e) TBDPSCl, $i \mathrm{Pr}_{2}$ EtN, DMAP, $\mathrm{CH}_{2} \mathrm{Cl}_{2}, 98 \%$; (f) $\left[\mathrm{RhCl}(\mathrm{coe})_{2}\right]_{2}, \mathrm{PCy}_{3}, \mathrm{MgBr}_{2}$, toluene, $180{ }^{\circ} \mathrm{C}, 50 \%, 92 \%$ ee; (g) $\mathrm{Br}_{2}, \mathrm{CH}_{2} \mathrm{Cl}_{2},-78{ }^{\circ} \mathrm{C}, 94 \%$; (h) 2-methylthio-4-trimethylstannylpyrimidine, ${ }^{6}$ $\mathrm{Pd}_{2}(\mathrm{dba})_{3} \cdot \mathrm{CHCl}_{3}, \mathrm{PPh}_{3}, \mathrm{LiCl}, \mathrm{CuI}$, dioxane, $170{ }^{\circ} \mathrm{C}, 85 \%$; (i) $\mathrm{OXONE}^{\circledR}, \mathrm{THF}, \mathrm{H}_{2} \mathrm{O}, 79 \%$; (j) propylamine, $78 \%$; (k) $\mathrm{Bu}_{4} \mathrm{NF}, \mathrm{THF}, 100 \%$. 


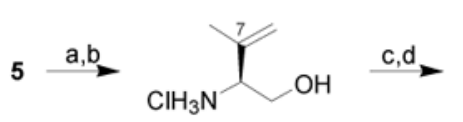

10

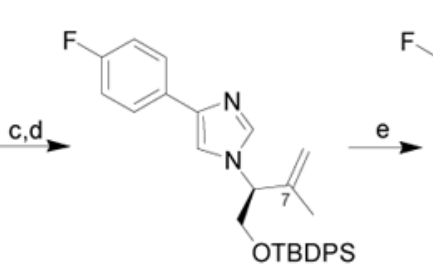

11

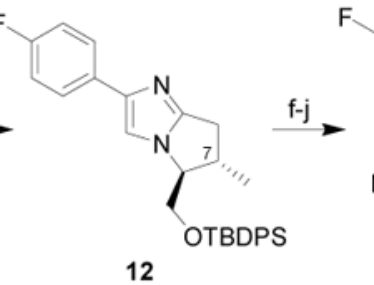

12

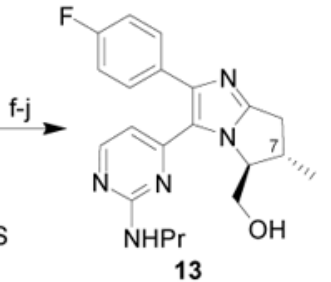

13

Scheme 2.

Synthesis of C7 Methyl Bicyclo bis-Arylimidazole Derivative Conditions: (a) isopropenylmagnesium bromide, $\mathrm{CH}_{2} \mathrm{Cl}_{2},-78{ }^{\circ} \mathrm{C}$ to $\mathrm{rt}, 90 \%$ (single diastereomer); (b) $4 \mathrm{~N} \mathrm{HCl}, \mathrm{CH}_{3} \mathrm{OH}, 96 \%$; (c) 4-fluorophenyl tosylmethyl isonitrile, glyoxylic acid, ${ }^{3} \mathrm{~K}_{2} \mathrm{CO}_{3}$, DMF; (d) TBDPSCl, $i \mathrm{Pr}_{2} \mathrm{EtN}$, DMAP, $\mathrm{CH}_{2} \mathrm{Cl}_{2}, 86 \%$ (over 2 steps); (e) [RhCl (coe) $\left.{ }_{2}\right]_{2}, \mathrm{PCy}_{3}, \mathrm{MgBr}_{2}$, toluene, $180{ }^{\circ} \mathrm{C}, 61 \%, 3: 1 \mathrm{dr}, 98 \%$ ee; (f) $\mathrm{Br}_{2}, \mathrm{CH}_{2} \mathrm{Cl}_{2},-78{ }^{\circ} \mathrm{C}, 96 \%$; (g) 2-methylthio-4-trimethylstannylpyrimidine, ${ }^{6} \mathrm{Pd}_{2}(\mathrm{dba})_{3} \cdot \mathrm{CHCl}_{3}, \mathrm{PPh}_{3}, \mathrm{LiCl}, \mathrm{CuI}$, dioxane, $170{ }^{\circ} \mathrm{C}, 66 \%$; (h) OXONE ${ }^{\circledR}, \mathrm{THF}, \mathrm{H}_{2} \mathrm{O}, 77 \%$ (single diastereomer); (i) propylamine, 93\%; (j) TBAF, THF, $87 \%$. 


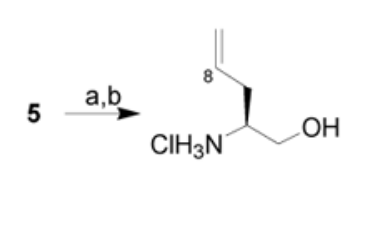

14

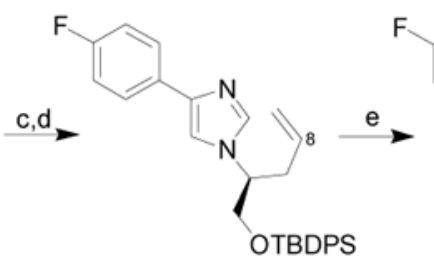

15

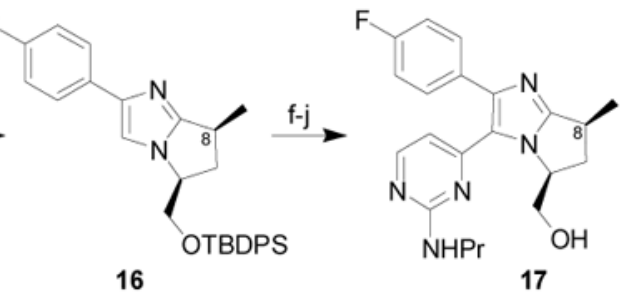

Scheme 3.

Synthesis of C8 Methyl Bicyclo Bis-Arylimidazole Derivative

Conditions: (a) allylmagnesium bromide, $\mathrm{CH}_{2} \mathrm{Cl}_{2},-78^{\circ} \mathrm{C}$ to rt, $92 \%$ (single diastereomer); (b) 4N HCl, $\mathrm{CH}_{3} \mathrm{OH}, 94 \%$; (c) 4-fluorophenyl tosylmethyl isonitrile, ${ }^{3}$ glyoxylic acid, $\mathrm{K}_{2} \mathrm{CO}_{3}$, DMF; (d) TBDPSCl, $i \mathrm{Pr}_{2} \mathrm{NEt}$, DMAP, $\mathrm{CH}_{2} \mathrm{Cl}_{2}, 78 \%$ (over 2 steps); (e) $\left[\mathrm{RhCl}(\mathrm{coe})_{2}\right]_{2}, \mathrm{PCy}_{3}$, $\mathrm{MgBr}_{2}$, toluene, $180{ }^{\circ} \mathrm{C}, 52 \%, 92 \%$ ee; (f) $\mathrm{Br}_{2}, \mathrm{CH}_{2} \mathrm{Cl}_{2},-78{ }^{\circ} \mathrm{C}, 80 \%$; (g) 2-methylthio-4trimethylstannylpyrimidine, ${ }^{6} \mathrm{Pd}_{2}(\mathrm{dba})_{3} \cdot \mathrm{CHCl}_{3}, \mathrm{PPh}_{3}, \mathrm{LiCl}, \mathrm{CuI}$, dioxane, $170{ }^{\circ} \mathrm{C}, 84 \%$; (h) OXONE ${ }^{\circledR}$, THF, $\mathrm{H}_{2} \mathrm{O}$; (i) propylamine, $91 \%$ (over 2 steps); (j) TBAF, THF, 99\%. 
Table 1

Inhibition of c-Jun N-Terminal Kinase 3

\begin{tabular}{cccc}
\hline Inhibitor & $\mathbf{I C}_{\mathbf{5 0}}(\mathbf{n M})^{\boldsymbol{a}, \boldsymbol{b}}$ & Inhibitor & $\mathbf{I C}_{\mathbf{5 0}}(\mathbf{n M})^{\boldsymbol{a}, \boldsymbol{b}}$ \\
\hline $\mathbf{1}$ & $5.38( \pm 1.40)$ & ent $-\mathbf{1 3}$ & $1.63( \pm 0.34)$ \\
$\mathbf{1 3}$ & $5.29( \pm 1.25)$ & ent $-\mathbf{1 7}$ & $8.10( \pm 1.82)$ \\
\hline
\end{tabular}

${ }^{a}$ Homogeneous time resolved fluorescence assay performed in quadruplicate.

${ }^{b}$ IC50 values confirmed using standard radioactivity assay (see Supporting Information). 